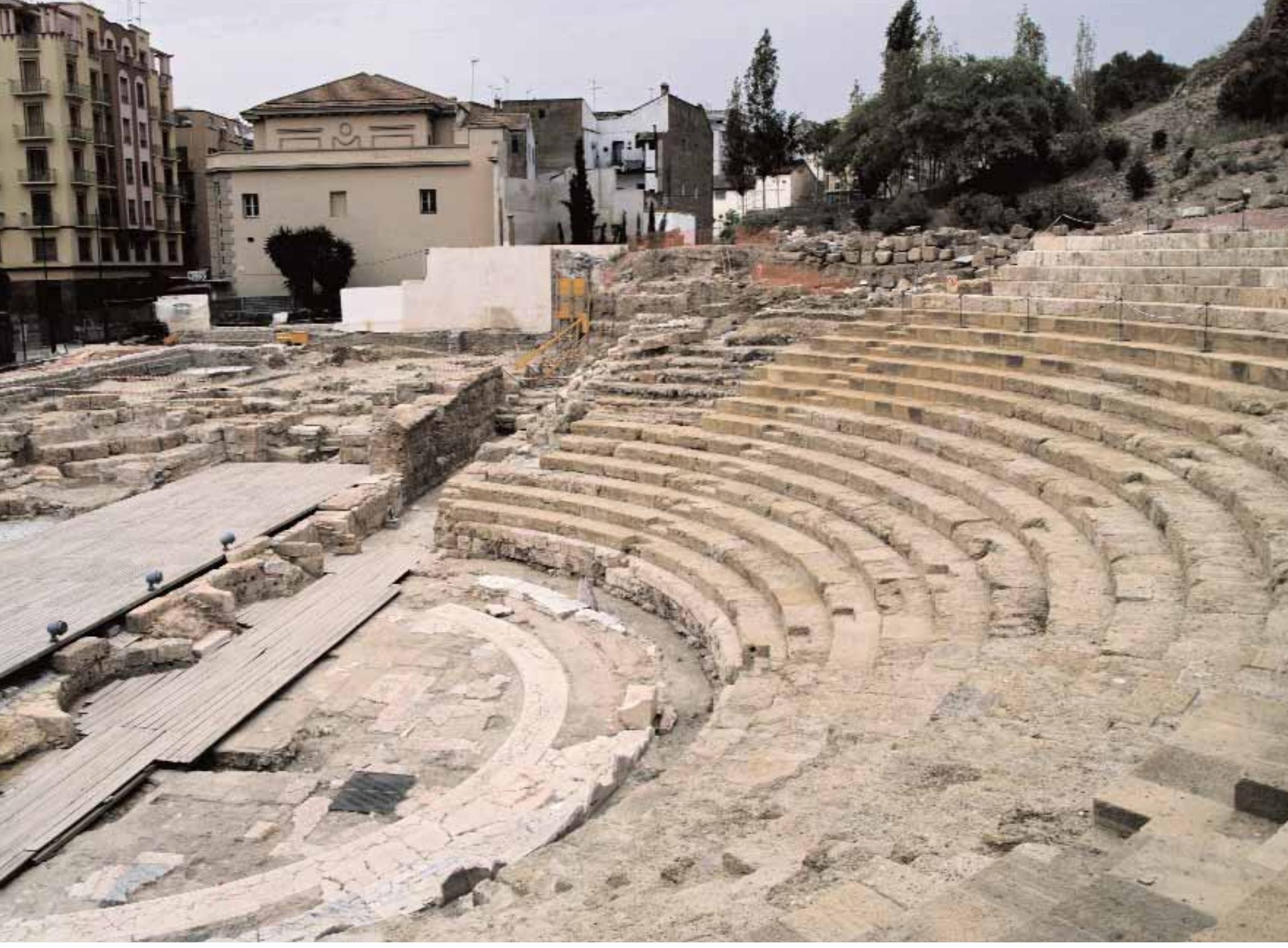

(1) Teatro Romano de Málaga / ISABEL Duco, IAPH

condiciones de equilibrio sostenible no debe aceptarse como una inevitable uniformidad a la que conduce el modelo de apropiación contemporáneo basado en una coyuntura de explotación ausente en la que el capital se desentiende de los valores sociales y culturales.

De acuerdo con las teorías sobre el paisaje hay un discurso productivo del paisaje a nivel dialéctico: la unidad del conjunto dominada por la percepción y la diferenciación de los elementos constitutivos derivada del conocimiento de todas sus partes, que tiene un gran alcance en los paisajes culturales por su vocación de trascender y asociar el trabajo de los colectivos sociales a la construcción de un espacio altamente cualificado (Declaración de San Antonio. ICOMOS, 1996).

Nada de esto escapa a la situación actual de los paisajes incluidos en la RAYA, donde se han integrado sitios arqueológicos de muy diversas características, distribuidos por todas las provincias andaluzas como muestra de las distintas formas de percibir y usar el medio por sociedades muy distantes en el tiempo. En mayor o menor grado han perdido su contexto y función original, y han sido recuperados para profundizar en el conocimiento del pasado, disfrutarlos en el presente y preservarlos para el futuro, a la vez que cualifican paisajes urbanos y rurales.

Dicha cualificación se alcanza a través de una doble vía. Por un lado, la presencia de sitios arqueológicos complejos y bien conservados of rece la posibilidad de profundizar en el conocimiento de los paisajes pretéritos, fundamento ineludible en la gestión de los paisajes culturales actuales. Por otro lado, su existencia imprime un carácter singular al lugar en el que se ubican, dotándolos de una trascendencia histórica perceptible que afianza su identidad frente a tendencias territoriales que apuestan por una uniformidad banal opuesta a la riqueza de lo diverso. 


\section{Teatro romano de Málaga. Problemas urbanísticos y paisajísticos del yacimiento}

El exponente más significativo de la ciudad romana de Malaca es, sin duda alguna, su teatro; edificio construido al pie de la colina origen de la ciudad, en las inmediaciones de un puerto al abrigo de los vientos y próximo a la desembocadura de un río. Resulta evidente que, tanto ayer como hoy, nos encontramos en el corazón de la ciudad; por él discurrían los restos fenicios, se desarrollaba la ciudad romana, la ciudad bizantina, y cómo no, la musulmana. Este tejido medieval orgánico, presidido por la Alcazaba y el castillo de Gibralfaro, y las aperturas decimonónicas, son las trazas urbanas donde se asientan las arquitecturas del siglo XIX y los restos que perduran del siglo XVII y XVIII. Este legado arquitectónico que destaca por su homogeneidad, orden compositivo, armonía de escalas y ocupación parcelaria sencilla junto a la Alameda, el Parque o la lámina que conforma el Puerto y los promontorios de la ciudad con sus ricas y variadas especies arbóreas, constituye un auténtico Paisaje Cultural. Así pues, en este corazón histórico y ecológico, se encuentra el lugar formado por el Museo Picasso, el Teatro Romano, la Alcazaba-Gibralfaro y la Aduana (Museo de Málaga).

La recuperación de la fortaleza árabe en el marco de monumento histórico, la transformación de la trama islámica a los pies de la Alcazaba con la apertura y ensanche de calle Alcazabilla y la decisión de construir el Palacio de Archivos, Bibliotecas y Museos, ubicado a los pies de la fortaleza árabe y a orillas de la nueva vía urbana, marcan y definen el espacio transformado que posibilitará el descubrimiento del Teatro Romano de Málaga en el verano de 1951. Las aperturas de Alcazabilla, junto a las de calle Larios y Molina Larios, fueron las primeras grandes operaciones transformadoras del centro, y estaban encaminadas a abrir relaciones norte-sur, hasta entonces muy forzadas por el viario de reminiscencia islámica. La calle Alcazabilla, que nace desde el principio como una calle atípica, final de un itinerario donde las fachadas van desapareciendo convirtiéndose en una calle institucional y cultural por los edificios que recorre, se constituye en estos momentos como un enclave determinante del futuro de la ciudad histórica.

El vacío aparecido, producto de la demolición de la Casa de la Cultura, requiere una articulación paisajística adecuada y sensible que considere la recuperación del Teatro con las murallas de la Alcazaba, los jardines de Ibn Gabirol, la Aduana y los accesos a la Alcazaba. También queda por solucionar el espacio que relacione el Teatro con la calle Alcazabilla y que tenga en cuenta los restos arqueológicos que perviven en el subsuelo.

La limpieza, la replantación parcial de la ladera y el adecentamiento de las medianeras de los edificios colindantes con el monumento fueron las primeras actuaciones abordadas en el seno del proyecto para resolver problemas urgentes de acondicionamiento del contorno de este Bien de Interés Cultural. Sin embargo, el Teatro, sometido a un delicado y complejo estado de conservación y de inserción urbana, requiere la puesta en marcha de un conjunto de proyectos que permita, además de completar la lectura del objeto, hacer posible la visita a este edificio tan singular y potenciar su extraordinario valor paisajístico y urbano, insertando el gran vacío de la ladera de la Alcazaba-Gibralfaro mediante la articulación adecuada entre el monumento y su espacio urbano.

Román Fernández-Baca Casares, Instituto Andaluz del Patrimonio Histórico. Manuel Corrales Aguilar, Delegación Provincial de Cultura de Málaga 